\title{
Advances in the Molecular Pathophysiology, Genetics, and Treatment of Primary Ovarian Insufficiency
}

Ilpo Huhtaniemi, ${ }^{1}$ Outi Hovatta, ${ }^{2}$ Antonio La Marca, ${ }^{3}$ Gabriel Livera, ${ }^{4}$ Danielle Monniaux, ${ }^{5}$ Luca Persani, ${ }^{6, *}$ Abdelkader Heddar, ${ }^{7}$ Katarzyna Jarzabek, ${ }^{8}$ Triin Laisk-Podar, ${ }^{9,10}$ Andres Salumets, ${ }^{9,10}$ Juha S. Tapanainen, ${ }^{11,12}$ Reiner A. Veitia, ${ }^{13}$ Jenny A. Visser, ${ }^{14}$ Peter Wieacker, ${ }^{15}$ Slawomir Wolczynski, ${ }^{16}$ and Micheline Misrahi ${ }^{7, *}$

Primary ovarian insufficiency (POI) affects $~ 1 \%$ of women before 40 years of age. The recent leap in genetic knowledge obtained by next generation sequencing (NGS) together with animal models has further elucidated its molecular pathogenesis, identifying novel genes/pathways. Mutations of $>60$ genes emphasize high genetic heterogeneity. Genome-wide association studies have revealed a shared genetic background between POI and reproductive aging. NGS will provide a genetic diagnosis leading to genetic/therapeutic counseling: first, defects in meiosis or DNA repair genes may predispose to tumors; and second, specific gene defects may predict the risk of rapid loss of a persistent ovarian reserve, an important determinant in fertility preservation. Indeed, a recent innovative treatment of $\mathrm{POI}$ by in vitro activation of dormant follicles proved to be successful.

\section{Introduction}

Primary ovarian insufficiency (POI), affects $\sim 1 \%$ of women before 40 years of age, thus being a relatively frequent syndrome [1]. $\mathrm{POI}$ is often diagnosed too late, causing irreversible impairment to the fertility and well-being of the affected women. Recent data indicate that $\mathrm{POI}$ is associated with significant morbidity and mortality. Several of these risks are direct consequences of extra-ovarian defects, generated by the gene mutations that underlie some forms of POI [2]. The clinical relevance of POI has exponentially increased only very recently, particularly in economically advanced countries, due to the frequent choice of women to conceive after 30 years of age and the increased life expectancy.

POl can manifest as pubertal delay and primary amenorrhea (PA), secondary amenorrhea (SA), or oligomenorrhea of $>4$ months. Recurrence of menses and pregnancies can occur in up to $22 \%$ of cases with SA for up to 4 months [3], but spontaneous resumption of follicle activity is exceptional in cases with long-lasting SA. The POI-associated hypergonadotropic hypogonadisms is defined as elevation of follicle-stimulating hormone (FSH) (see Glossary) $\geq$ $25 \mathrm{IU} / \mathrm{L}$ confirmed twice, 30 days apart, in women with SA [1]. The ovarian reserve (OR) can be evaluated by transvaginal ovarian ultrasound (US) with antral follicular count and/or by antiMüllerian hormone (AMH) determination. In both PA and SA cases, it is possible to uncover a certain OR by US and AMH measurement [4].

\section{Highlights}

The mechanisms underlying the formation of the ovarian reserve are generally well conserved, from Drosophila to mammals. Owing to this high degree of conservation, factors shown to regulate the ovarian reserve in mouse models are all potential candidates for identifying mutations associated with $\mathrm{POI}$ in humans.

With the generation of genetically modified mice, much insight has been gained into the mechanisms that control the formation of the ovarian reserve and trigger the activation of primordial follicles.

Comparison with animal models is complicated by the fact that the phenotype of complete gene deletion in knockout models may not be mimicked by single gene mutations.

Recently innovative treatment for $\mathrm{POI}$ based on in vitro activation of the dormant primordial follicular pool has been developed.

${ }^{1}$ Institute of Reproductive and Developmental Biology, Department of Surgery \& Cancer, Imperial College London, Hammersmith Campus, London W12 ONN, UK

${ }^{2}$ Karolinska Institute, Stockholm, Sweden, Nova Southeastern University, Fort Lauderdale, FL, USA ${ }^{3}$ Mother-Infant Department, University of Modena and Reggio Emilia, Modena 41100, Italy

${ }^{4}$ Laboratory of Development of the 
Low/undetectable AMH indicates a dramatic diminution of the OR, predicting poor success of fertility preservation. However, follicular activity and pregnancy were rescued in POI patients with undetectable serum $\mathrm{AMH}$ after in vitro activation (IVA) and autotransplantation of fresh tissue [5].

Menstrual irregularities, such as oligoamenorrhea or polymenorrhea, can anticipate the onset of SA, but not as a rule.

Many clinicians are unaware of the advantages of early POI diagnosis and fail to provide integrated personal care to address all the clinical needs. Here, we review the pathophysiology, genetics and treatment of POI in order to shed light on: (i) the manifestations that should alert clinicians, and (ii) the novel multidisciplinary approaches for improved clinical management.

latrogenic $\mathrm{POI}$ frequently occurs in cancer survivors of young age. A variety of environmental factors, such as infections or pollutants like phthalates, bisphenol A, and polycyclic aromatic hydrocarbons from cigarette smoke, have a harmful impact on reproduction and are implicated in about $10 \%$ of POI [6]. Pollutants can affect ovarian follicles mainly by binding to estrogen or aryl hydrocarbon receptors, severely affecting follicle growth and viability [7]. Moreover, pollutants can cause germline epigenetic modifications, thereby accounting for transgenerational inheritance of reduced OR [8]. About 5\%-30\% of POI may have autoimmune origin [9], which is of potential interest because an early diagnosis may allow prompt treatment and eventually prevent damage to the OR.

The incidence of familial cases of premature ovarian failure was reported to vary from $4 \%$ to $31 \%[10,11]$. Thorough evaluation of alleged affected relatives showed a lower incidence $(12.7 \%)$ than the original family history suggested [12]. Pedigree studies on affected families showed a mode of inheritance suggestive of autosomal dominant or recessive transmission with highly variable expressivity or X-linked inheritance with incomplete penetrance [13]. Approximately $2-6 \%$ of women with sporadic $\mathrm{POI}$ have a premutation of the FMR1 gene [14]. Other known genetic causes are responsible for a small proportion of POls.

Most causes of $\mathrm{POI}$ are unknown. Understanding the underlying molecular mechanisms is essential to develop strategies for prevention, early diagnosis, and improved management of POI.

A great leap in the genetics of $\mathrm{POI}$ was achieved by the major methodological progress of next generation sequencing (NGS) and in particular whole exome sequencing (WES). The knowledge of more than 60 genes has enabled genetic diagnosis by NGS and provided a flow chart for the diagnosis and treatment of POI (see below). A novel innovative treatment of the infertility of these patients has recently emerged.

\section{Establishment of the OR}

Primordial follicles (PFs) constitute the entire OR. Mechanisms that regulate the formation of the PF pool and the rate by which it is used will determine the duration of the fertile lifespan (Figures 1 and 2). OR formation is a similar process in humans and mice, and in recent years, much insight has been gained into the molecular mechanisms involved.

At 20 weeks of gestation, a pair of human ovaries contains close to 7 million germ cells [15]. A rapid loss of follicles in fetal life results in about 1-2 million oocytes at birth. Prior to puberty, the number declines further, to 300 000-400 000. During reproductive life, the number declines
Gonads, Unit of Genetic Stability, Stem Cells and Radiation: UMR 967, INSERM; CEA/DRF/iRCM/SCSR; Univ. Paris Diderot, Sorbonne Paris Cité; Univ. Paris-Sud, Université ParisSaclay, Fontenay aux Roses, F-92265, France

${ }^{5}$ UMR85 PRC, Physiology of Reproduction and Behavior, INRA, CNRS, IFCE, University of Tours, 37380 Nouzilly, France

${ }^{6}$ Department of Clinical Sciences \& Community Health, University of Milan, Milan 20122, Division of Endocrine and Metabolic Diseases, Istituto Auxologico Italiano, Milan 20149, Italy

${ }^{7}$ Medical Faculty, Univ. Paris Sud and Paris Saclay, Bicetre Hospital 94275 , Le Kremlin Bicêtre, France ${ }^{8}$ Department of Biology and Pathology of Human Reproduction, Institute of Animal Reproduction and Food Research, Polish Academy of Sciences, 10-748 Olsztyn, Poland ${ }^{9}$ Women's Clinic, Institute of Clinical Medicine, University of Tartu, L. Puusepa 8, Tartu, Estonia ${ }^{10}$ Competence Centre on Health Technologies, 50410, Estonia

${ }^{11}$ Department of Obstetrics and Gynecology, University of Helsinki and Helsinki University, Hospital, Helsinki 00029, Finland

${ }^{12}$ Department of Obstetrics and Gynecology, University Hospital of Oulu, University of Oulu, Medical Research Center Oulu and PEDEGO Research Unit, P.O BOX 23, FI-90029 OYS, Oulu, Finland

${ }^{13}$ Molecular Oncology and Ovarian Pathologies Université Paris-Diderot/

Paris 7, Institut Jacques Monod, 15 Rue Hélène Brion, Paris Cedex 13, France

${ }^{14}$ Dept. of Internal Medicine, Erasmus University Medical Center, P.O. Box 2040, 3000 CA, Rotterdam, The Netherlands

${ }^{15}$ Institute of Human Genetics, University Hospital of Münster, Vesaliusweg 12-14 D48149 Münster, Germany

${ }^{16}$ Department of Reproduction and Gynecological Endocrinology, Medical University of Bialystok, Sklodowskiej 24A, 15-276 Bialystok, Poland

${ }^{*}$ Correspondence:

micheline.misrahi@aphp.fr, luca.persani@unimi.it (M. Misrahi). 
steadily until a critical threshold of 1000 PFs is reached [15]. Below this threshold, ovulations cannot be supported, yielding menopause.

Oocytes derive from primordial germ cells (PGCs), which emerge from the extraembryonic mesoderm and migrate to the genital ridge (Figure 1). Upon arrival in the gonad, the PGCs will yield interconnected oogonia which, together with aggregation of germ cells, create so-called germ cell cysts [16]. Somatic cell-derived factors, in particular bone morphogenetic proteins (BMPs) and Wnt3/ß-catenin, control the commitment, migration, and proliferation of PGCs. These signaling pathways induce the reacquisition of pluripotency, which is driven by Prdm1 and Prdm14. Subsequently, pluripotency genes (Pou5F1 encoding Oct4, Nanog, Klf4, Lin 28a) and germline specific genes (early genes: Nanos3, Kitlg, Tfapc2, Dppa3; late genes: Ddx4 or Vasa, Mael, Dazl) play important roles in the migration, proliferation, and survival of PGCs [16]. After cessation of mitosis, the oogonia enter meiosis ( 13.5 days postconception in mouse and asynchronously 10-12 weeks of gestation in humans) and become oocytes (Figures 1 and 2). They will progress through the initial stages of prophase I until arrest in the diplotene stage of prophase I. The initiation of meiosis is dependent on expression of Dazl, which induces responsiveness to retinoic acid, which in turn induces Stra8 (stimulated by retinoic acid)dependent and -independent pathways, and subsequently the activation of the synaptonemal complex (SC) proteins Sycp1, 2, and 3. Recently, Taf4b was identified as an upstream regulator of several meiotic genes, including Stra8 and Dazl, in both mice and women [17]. Additionally it recently appeared that post-transcriptional mechanisms involving the Ythdc2/Meioc complex are mandatory for the proper mitotic/meiotic transition [18,19].

The next developmental step in follicle formation is the breakdown of germ cell cysts between E17.5 and 5 days postpartum in mice and at midgestation (10-13 weeks of gestation) in humans (Figure 1). Upon breakdown, pregranulosa cells are recruited to encapsulate a single oocyte to form PF, and oocytes undergo meiotic arrest. Gdf9, Bmp15, FoxL2, Nobox, Figla, Notch2, and Adam10 include some of the factors that affect the timing of cyst breakdown and differentiation of pregranulosa cells $[20,21]$. Furthermore, estrogen signaling plays an inhibitory role in cyst breakdown [22]. At the cessation of mitosis, the number of oogonia has increased exponentially. However, it is estimated that during cyst breakdown, two-thirds of the oocytes are lost through programmed cell death, including apoptosis and autophagy [23].

Genetic modification in mice has been beneficial for identification of the crucial genes in establishment of the OR. Mutations in several of these genes have been identified in women with $\mathrm{POI}$

Recent Advances in the Genetics of POI in Humans

The genetic causes of $\mathrm{POI}$ are highly heterogeneous, with isolated or syndromic forms. Reproductive and extra-reproductive features of syndromic $\mathrm{POI}$ are described in Table 1. The genes involved are listed in Figures 1-3 and Table 1.

\section{Meiosis, DNA Repair, and POI}

Mutations of meiotic and DNA repair genes are responsible for syndromic and nonsyndromic POI (Figures 2 and 3). There have been recent major advances in the identification of these genes as a cause of POI through NGS studies.

Oocytes enter into and progress through meiosis prophase I during fetal life. Mutations in meiotic genes usually impair meiotic progression and trigger oocyte death, as evidenced by several mouse models [24].

\section{Glossary}

Anti-Müllerian hormone (AMH): growth factor produced by the granulosa cells of growing follicles. Serum AMH level is an indirect marker of the ovarian reserve and declines with increasing age. Follicle-stimulating hormone (FSH): a pituitary-derived hormone that stimulates estrogen production, follicle growth, and selection of the preovulatory follicle. Serum FSH levels are elevated upon ovarian aging due to the loss of negative feedback signals. Normal FSH concentrations (IU/I) are: during follicular phase, 3.5-9.0; ovulatory phase, 7.0-21.5; luteal phase, 1.77.0; postmenopause, 26-140.

Homologous recombination (HR): a process that assures faithful repair of double strand breaks, one of the most dangerous DNA damages. HR relies on the invasion of a similar DNA matrix (the homologous chromosome during meiosis) as a template to repair the broken DNA. The products of this repair can either be a local replacement of DNA sequence or exchange of large chromosome fragments, respectively termed non-crossover and crossover. The meiotic crossovers are mandatory for proper segregation of chromosomes, thus precisely halving the genome in gametes. In vitro activation (IVA): although menstrual cycles cease in $\mathrm{POI}$ patients, some of them retain residual dormant ovarian follicles. A new infertility treatment has been developed, which enables $\mathrm{POI}$ patients to conceive using their own eggs, by activation of the residual dormant follicles through in vitro manipulation of signaling pathways responsible for follicular quiescence. Luteinizing hormone (LH): a pituitary-derived hormone that triggers ovulation. Serum LH levels increase upon ovarian aging due to the loss of negative feedback signals. Meiosis: meiosis is the universal cellular process in eukaryotes that allows formation of the haploid reproductive cells.

DNA double strand breaks (DSBs): DSBs are programmed DNA breaks generated early during prophase I and catalyzed by the sporulation 11 homolog (SPO11) enzyme. DSBs are concentrated in 
During prophase I, meiosis requires the establishment of the SC and the generation and repair of DNA double strand breaks (DSBs) [25]. Cohesin rings surrounding the chromosomes contribute to proper formation of the SC. Stromal antigen 3 (STAG3), Recombination 8 (REC8), Structural Maintenance of Chromosomes 1B (SMC1B), and Radiation Sensitive 21-Like $(R A D 21 L)$ encode proteins belonging to the cohesin family and are specific to meiosis. Exome sequencing revealed that the two copies of STAG3 are inactivated by a truncating mutation in patients with $\mathrm{POI}$ from a consanguineous family [26]. Of note, one patient had bilateral ovarian tumors. Inactivation of Stag3 in mice impairs meiotic progression and leads to oocyte death [27]. SMC1B and REC8 have also been proposed to be associated with POI [28]. The SC is formed by several proteins organized in lateral and central elements [25]. A homozygous mutation of the Synaptonemal Complex Central Element Protein 1 (SYCE1) was described in two sisters with POI in a consanguineous family [29], consistent with infertility observed in animal models [30].

Mini Chromosome Maintenance 8 and 9 are helicase members of the MCM family. MCM8-9 complex is required for homologous recombination (HR)-mediated repair of DSB, facilitating DNA resection by the MRN complex [31]. Lack of Mcm8 or Mcm9 in mice induces meiotic defects, oocyte degeneration, and ovarian tumors. Regarding MCM8, the analysis of three consanguineous sisters with hypothyroidism and $\mathrm{POI}$ revealed the presence of a pathogenic variant [32]. The study of several other consanguineous families allowed the identification of homozygous variants for MCM8 and MCM9 in the affected patients [33-36].

For MCM8 and MCM9, the repair of chromosomal breaks in fibroblasts or lymphocytes of the patients was found to be altered [32,33].

Meiotic DSB repair requires the loading of two recombinases, RAD51 and its meiotic paralog DMC1, on DNA. The activities of DMC1 and RAD51 are regulated by many factors, including homologouspairing protein 2 homolog (HOP2/PSMC3IP). Only one homozygous mutation in DMC1 has been reported in women with $\mathrm{POI}$ [37]. The study of a Palestinian family using homozygosity mapping and NGS allowed the detection of a homozygous microdeletion in the PSMC3IP gene [38]. The possibility of a meiotic defect in the patients studied was not examined directly.

The recombination intermediates need to be stabilized to promote the formation of crossovers. This step requires helicases such as HFM1 and the dimer MSH4-MSH5. Exome sequencing has uncovered composite heterozygous mutations in HFM1 in a cohort of patients with sporadic $\mathrm{POI}$ and SA [39,40], in agreement with the phenotype of the $h \mathrm{fm}^{-/-}$mice. Exome sequencing recently identified a deleterious homozygous donor splice-site mutation in $\mathrm{MSH} 4$ in a case of familial POI. This mutation was associated with the generation of internally deleted $\mathrm{MSH} 4$ protein [41]. Similarly, a homozygous mutation in MSH5 in two sisters with POI has recently been reported [42]. The adverse effect of this mutation was confirmed in a mouse model and proven to impair DNA repair.

The final step of recombination is the resolution of recombination intermediates. The resolution of the double Holliday junctions is believed to rely on the heterodimer MLH1-MLH3, and the exonuclease EXO1. Mice lacking either Mlh1 or Mlh3 are sterile. Human mutations reported in MLH1 are largely associated with colorectal cancer and Lynch syndrome, with no systematic impact on fertility.

Three RecQ helicases, namely BLM (Bloom syndrome), RECQL4 (RecQ protein-like 4), and WRN (Werner syndrome) are proposed to be involved in meiotic recombination, albeit their 'hotspots' designated by PR domain containing 9 (PRDM9), through the deposition of trimethylation on lysine 4 of histone 3.

Next generation sequencing (NGS): also known as highthroughput sequencing, describes modern sequencing technologies that allow the sequencing of thousands to millions of DNA molecules simultaneously. It allows sequencing multiple genes and multiple individuals at the same time. Nonhomologous end-joining (NHEJ): a DSB repair pathway often opposed to HR. NHEJ directly ligates broken DNA ends together. It is believed to result in low repair fidelity in the absence of a homologous sequence to guide DNA repair, as in HR.

Ovarian reserve (OR): a term describing the quality and number of resting oocytes within primordial follicles, and considered as a female's reproductive potential. PI3K/Akt signaling pathway: the phosphatidylinositol 3-kinase/Akt/ mammalian target of rapamycin (PI3K/Akt/mTOR) signaling pathway, regulating various stages of folliculogenesis. Studies in most genetic mouse models have revealed an essential role of this pathway in primordial follicle activation.

Primordial germ cells (PGCs): the primary cells that form the progenitors of gametes. PGCs will populate the embryonic gonads and differentiate into either oocytes or spermatocytes.

Whole exome sequencing (WES): sequencing by NGS, the proteincoding region of the human genome (exome) that represents $<2 \%$ of the genome, but contains most known disease-related variants. 
(A)

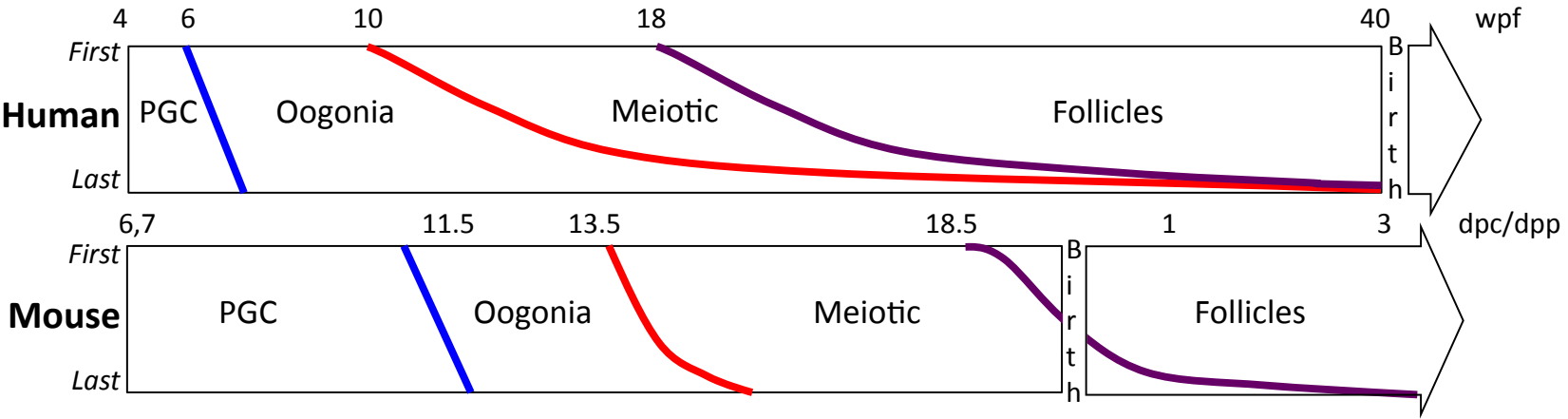

(B)
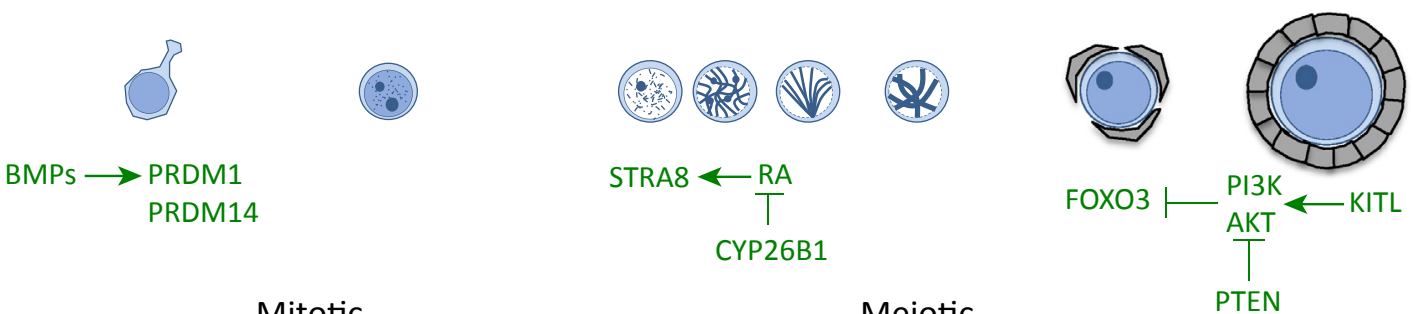

(C)

Mitotic

Meiotic



\begin{tabular}{cc|}
\hline PGC & Oogonia \\
specification & differentiation \\
& \\
Migration & \\
Colonization &
\end{tabular}

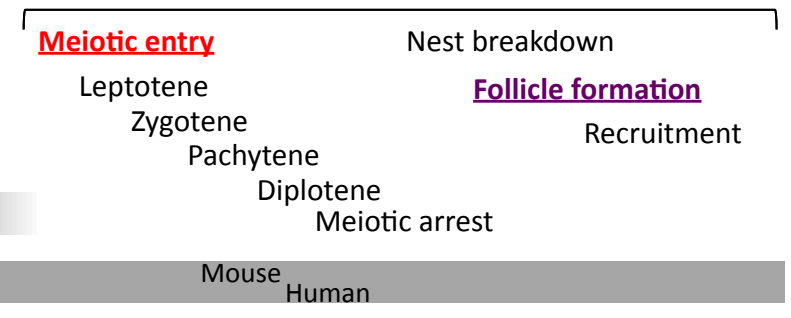

STRA8/SYCP3

NOBOX/TP63

Trends in Endocrinology \& Metabolism

Figure 1. Formation of the Ovarian Reserve in Humans and Mice. (A) Chronology of female germ cell development from primordial germ cell (PGC) specification until follicle formation (purple). Appearance of oogonia and meiotic cells are defined respectively by the blue and red lines [weeks post fertilization (wpf), days post conception (dpc), days postpartum (dpp)]. (B) Schematic presentation of the various germ cell stages. From left to right, migratory PGCs, oogonia, and pre-leptotene-, leptotene-, zygotene-, pachytene-, and diplotene-arrested oocytes in primordial and growing (primary) follicles are presented in blue. Key signaling pathways regulating PGC specification, meiotic entry, and follicle activation are provided in green. (C) Frequently used markers of the various germ cell stages. POU5F1 (OCT4), POU class 5 homeobox 1, and TFAP2C (AP2 $\gamma$ ) are retrieved in PGC and oogonia with stem cell potential. Deleted in azoospermia-like (DAZL) and DDX4 (VASA), DEAD box polypeptide 4, mark the gametogenic competency acquired when mouse germ cells colonize the gonad and later during oogonial differentiation in the human ovary. STRA8 is expressed at the mitotic/meiotic switch, in the pre-leptotene stage, and SYCP3 is a synaptonemal complex protein that labels the axes of the chromosomes during meiotic prophase I. NOBOX, NOBOX oogenesis homeobox, and tumor protein 63 (TP63), are retrieved in the nuclei of diplotene-arrested oocytes enclosed into follicles. BMPs, Bone morphogenic proteins; CYP26B1, cytochrome P450, family 26, subfamily B, polypeptide 1; FOXO3, forkhead box O3; KITL, kit ligand; PI3K, phosphoinositide-3-kinase; PRDM, PR domain containing 1, with ZNF domain (PRDM1/BLIMP1); PTEN, phosphatase and tensin homolog; RA, retinoic acid; STRA8, stimulated by retinoic acid 8.

function in mammals is not fully elucidated. These RecQ helicases are also mutated in human syndromes manifesting in premature aging, cancer, and often POI or reduced fertility [43-45].

Cockayne Syndrome B (CSB/ERCC6) encodes a protein involved in DNA repair. A heterozygous mutation in the CSB-piggyBac transposable element derived 3 (PGBD3) fusion geneinduced $\mathrm{POI}$ with the mutated protein exhibiting an altered response to DNA damage [46]. 


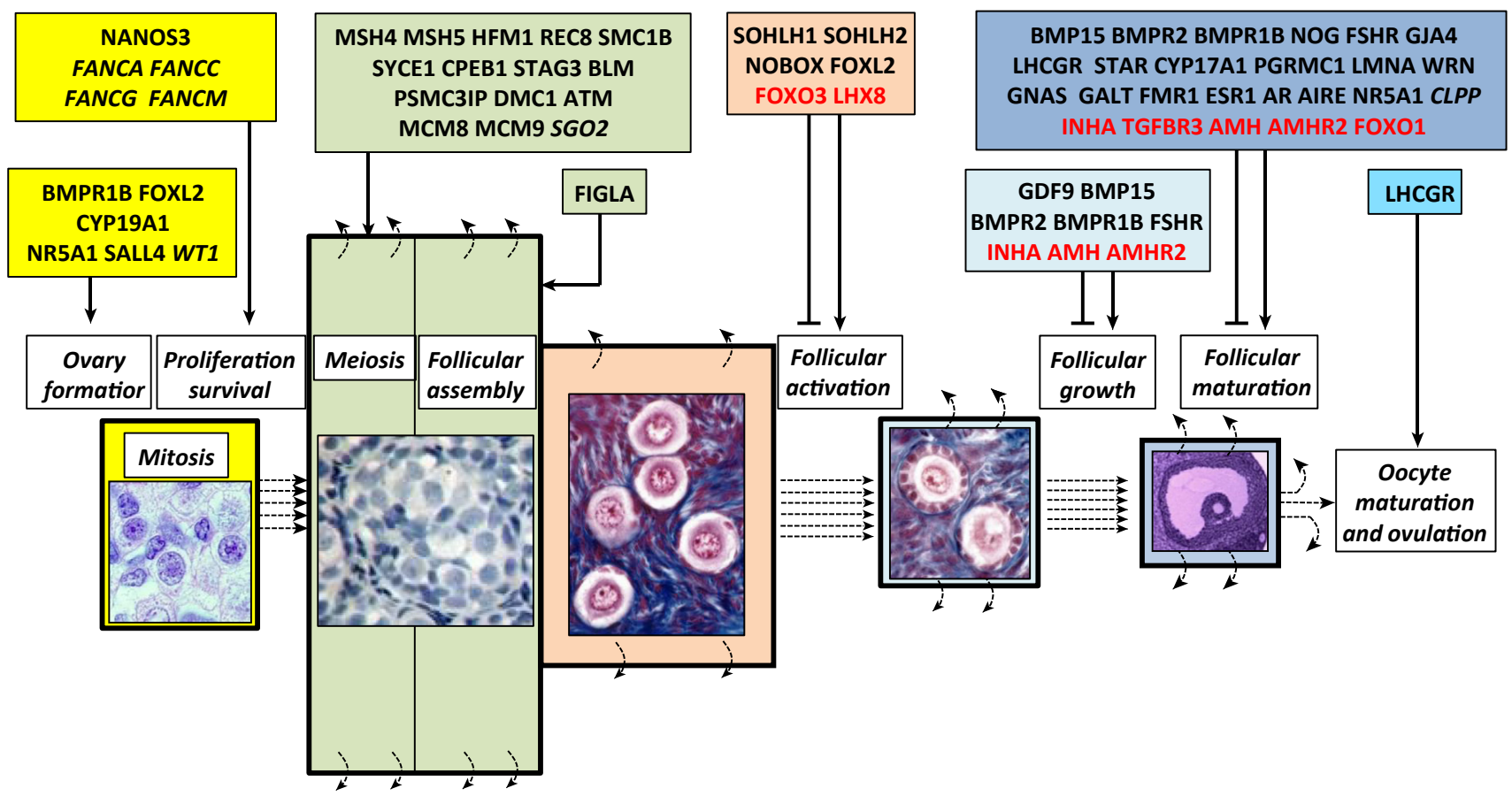

\begin{tabular}{|l|l|l|l|l|l|}
\hline PGC oogonia & Follicle formation & Primordial follicles & Primary follicles & Antral follicles & Ovulation \\
\hline
\end{tabular}

Cell attachment and migration: ANTXR1

Nuclear functions: NUP107

DNA damage, repair, replication: NBN, RECQL4, XRCC4, CSB-PGBD3, SPIDR, POF1B

Translational and post-translational regulations: EIF2B, RCBTB1, EIF4ENIF1

Mitochondrial function: AARS2, HARS2, LARS2, MT-ATP6/8, C10ORF2, KIAA0391, ERAL1, POLG

Peroxisomal function: HSD17B4

Metabolic defect: PMM2

Trends in Endocrinology \& Metabolism

Figure 2. Human Genes Associated with Primary Ovarian Insufficiency and Their Physiological Importance in Oogenesis, Folliculogenesis, and Other Functions. Genes with in vivo mutations associated with primary ovarian insufficiency (POI) in humans and the physiological importance of these genes in ovarian function are indicated. Oogenesis and folliculogenic processes are represented by a transit between different compartmental stages, depicted as boxes containing the cell populations. At each stage of oogenesis and folliculogenesis, an important part of the germ cell will die by apoptosis, depicted by a concomitant decrease in box sizes. The first compartment (yellow box) corresponds to the primordial germ cells (PGCs) when they differentiate into oogonia, the second compartment (green box) corresponds to follicle formation, which involves meiosis and follicular assembly processes and ends with establishment of the ovarian reserve of primordial follicles (pink box). From this reserve, follicular activation leads to the formation of primary follicles (light blue box). Then the growing follicles can reach the antral stage (dark blue box) and ovulate, or degenerate by atresia. Genes whose mutations are associated with POI are indicated at each stage of these developmental processes. The involvement of each gene at a specific stage of ovarian or follicular development is based on in vivo (presence/absence of follicles in biopsy samples, detection of antral follicles using ovarian ultrasound scanning or AMH measurements in women carrying mutations) or/and in vitro observations (culture experiments using human ovarian cortex or granulosa cells). For genes depicted in italic, information on their stage specific role is only available from mouse models. Genes associated with POI for which the stage-specific role is unknown are listed in the box, with their biological function (green font). The stimulating and inhibiting factors are depicted in black and red font, respectively. See text for references and [13].

Lastly, although meiotic DSB repair appears to rely on HR, a second process for DSB repair, the nonhomologous end-joining (NHEJ), allows the direct ligation of broken DNA ends to each other. X-ray repair cross-complementing protein 4 (XRCC4) and Ligase 4 (LIG4) are two proteins absolutely required for NHEJ. Syndromic $\mathrm{POI}$ was reported in a female patient with 
Table 1. Clinical Presentations of Syndromic POI. ${ }^{\mathrm{a}}$

\begin{tabular}{|c|c|c|c|c|c|}
\hline Diagnosis & $\begin{array}{l}\text { Menstrual } \\
\text { history }\end{array}$ & Ovarian phenotype & Particular features & OMIM \# & Gene(s) involved \\
\hline WT1-related XX-DSD & PA or SA & $\begin{array}{l}\text { Streak gonads, } \\
\text { partial ovarian dysgenesis }\end{array}$ & Nephropathy, diaphragmatic hernia & 194070 & WT1 \\
\hline SF1-related XX-DSD & PA or SA & $\begin{array}{l}\text { Streak gonads, } \\
\text { partial ovarian dysgenesis }\end{array}$ & Adrenal insufficiency & 612964 & NR5A1/SF1 \\
\hline BPES & PA or SA & Rare or absent follicles & $\begin{array}{l}\text { Blepharophimosis, ptosis, epicanthus } \\
\text { inversus }\end{array}$ & 110100 & FOXL2 \\
\hline FMR1 premutation & SA & Follicle depletion & $\begin{array}{l}\text { X-linked mental retardation in family. Fragile X } \\
\text { tremor/ataxia syndrome }\end{array}$ & 300624 & FMR1 \\
\hline $\begin{array}{l}\text { Autoimmune } \\
\text { polyendocrinopathy } \\
\text { syndrome. APS-PGA } \\
\text { type } 1\end{array}$ & PA or SA & Autoimmune oophoritis & $\begin{array}{l}\text { Addison disease, candidiasis, vitiligo, } \\
\text { hypoparathyroidism, diabetes mellitus, } \\
\text { hepatitis, malabsorption, keratopathy, } \\
\text { alopecia }\end{array}$ & 240300 & AIRE \\
\hline $\begin{array}{l}\text { Autoimmune APS- } \\
\text { PGA type } 3\end{array}$ & & Autoimmune oophoritis & $\begin{array}{l}\text { Autoimmune thyroid disease, atrophic } \\
\text { gastritis, vitiligo }\end{array}$ & & \\
\hline $\begin{array}{l}\text { Pseudohypopara } \\
\text { thyroidism }\end{array}$ & SA & $\begin{array}{l}\text { Follicular cysts but no } \\
\text { corpora lutea in one case }\end{array}$ & $\begin{array}{l}\text { Brachydactyly, short stature, hypocalcemia } \\
\text { and hyperphosphatemia, hypothyroidism, } \\
\text { obesity }\end{array}$ & \#103580 & GNAS \\
\hline Galactosemia & PA & $\begin{array}{l}\text { Streak ovaries or few } \\
\text { nonmaturated follicles }\end{array}$ & $\begin{array}{l}\text { Neonatal jaundice, failure to thrive, cirrhosis, } \\
\text { cataract, intellectual disability, food } \\
\text { intolerance, hypoglycemia, renal dysfunction. }\end{array}$ & 230400 & GALT \\
\hline $\begin{array}{l}\text { Disorders of } \\
\text { glycosylation (CDG1A) }\end{array}$ & PA & $\begin{array}{l}\text { Absent ovaries in some } \\
\text { patients by US or } \\
\text { laparoscopy }\end{array}$ & $\begin{array}{l}\text { Growth retardation, microcephaly, } \\
\text { encephalopathy, peripheral neuropathy, } \\
\text { retinitis pigmentosa, cardiac myopathy, } \\
\text { hepatomegaly, nephrotic syndrome, } \\
\text { psychomotor retardation }\end{array}$ & 212065 & PMM2 \\
\hline Ataxia telangiectasia & $\mathrm{PA}$ & & $\begin{array}{l}\text { Cerebellar ataxia, telangiectasia, recurrent } \\
\text { infections, malignancies, and increased levels } \\
\text { of alpha fetoprotein }\end{array}$ & 208900 & ATM \\
\hline $\begin{array}{l}\text { Nijmegen breakage } \\
\text { syndrome }\end{array}$ & PA or SA & Streak gonads, small ovaries & $\begin{array}{l}\text { Prenatal growth retardation, progressive } \\
\text { mental deterioration, microcephaly, recurrent } \\
\text { infections, increased risk for neoplasias such } \\
\text { as lymphoma }\end{array}$ & 251260 & NBN \\
\hline Fanconi anemia & PA or SA & $\begin{array}{l}\text { Decreased number of } \\
\text { primordial follicles }\end{array}$ & $\begin{array}{l}\text { Pancytopenia, small stature, microcephaly, } \\
\text { ear anomalies, heart defects, kidney } \\
\text { malformations, radial aplasia and thumb } \\
\text { deformities, intellectual disability, café-au lait- } \\
\text { spots }\end{array}$ & $\begin{array}{l}\# 227650 \\
\# 227645 \\
\# 614082\end{array}$ & $\begin{array}{l}\text { FANCA } \\
\text { FANCC } \\
\text { FANCG }\end{array}$ \\
\hline $\begin{array}{l}\text { XRCC4-related } \\
\text { disorder }\end{array}$ & SA & & $\begin{array}{l}\text { Short stature, microcephaly, developmental } \\
\text { delay, diabetes mellitus }\end{array}$ & \#616541 & $X R C C 4$ \\
\hline Bloom syndrome & SA & $\begin{array}{l}\text { Possibly accelerated follicular } \\
\text { atresia }\end{array}$ & $\begin{array}{l}\text { Premature aging with chromosomal } \\
\text { instability, short stature, skin rashes and } \\
\text { telangiectatic skin on sun-exposed areas, } \\
\text { increased risk for neoplasias, } \\
\text { immunodeficiency }\end{array}$ & \#210900 & $B L M$ \\
\hline Werner syndrome & SA & $\begin{array}{l}\text { Possibly accelerated follicular } \\
\text { atresia }\end{array}$ & $\begin{array}{l}\text { Premature aging with chromosomal } \\
\text { instability, pre- and postnatal growth } \\
\text { deficiency, sclerodermic skin changes, } \\
\text { cataract, arteriosclerosis, increased cancer } \\
\text { risk, diabetes mellitus }\end{array}$ & \#277700 & WRN \\
\hline $\begin{array}{l}\text { Rothmund-Thomson } \\
\text { syndrome }\end{array}$ & SA & Gonadotropin resistance & $\begin{array}{l}\text { Short stature, cataract, saddle nose, teeth } \\
\text { anomalies, premature graying of hair }\end{array}$ & \#268400 & RECQL4 \\
\hline
\end{tabular}


Table 1. (continued)

\begin{tabular}{|c|c|c|c|c|c|}
\hline Diagnosis & $\begin{array}{l}\text { Menstrual } \\
\text { history }\end{array}$ & Ovarian phenotype & Particular features & OMIM \# & Gene(s) involved \\
\hline $\begin{array}{l}\text { Hutchinson-Gilford } \\
\text { progeria }\end{array}$ & SA & Diminished follicular reserve & $\begin{array}{l}\text { Progeria, short stature, low body weight, early } \\
\text { loss of hair, lipodystrophy, scleroderma, } \\
\text { decreased joint mobility, osteolysis, } \\
\text { cardiomyopathy }\end{array}$ & \#176670 & LMNA \\
\hline GAPO & SA & Follicle depletion & $\begin{array}{l}\text { Growth retardation, alopecia, } \\
\text { pseudoanodontia, optic atrophy, high } \\
\text { forehead, midface hypoplasia }\end{array}$ & \#230740 & ANTXR1 \\
\hline Perrault syndrome & PA, SA & $\begin{array}{l}\text { Streak ovaries, } \\
\text { lack of ovaries, } \\
\text { small ovaries }\end{array}$ & $\begin{array}{l}\text { Deafness } \\
\text { Neurologic symptoms in PRLTS1, PRLTS3, } \\
\text { and PRLTS5 }\end{array}$ & $\begin{array}{l}\# 233400 \\
\# 614926 \\
\# 614129 \\
\# 615300 \\
\# 616138\end{array}$ & $\begin{array}{l}\text { HSD17B4, HARS2, } \\
\text { LARS2 CLPP } \\
\text { C10orf2, CLDN14+ } \\
\text { SGO2 } \\
\text { KIAA0391 } \\
\text { ERAL1 }\end{array}$ \\
\hline $\begin{array}{l}\text { Woodhouse-Sakati } \\
\text { syndrome }\end{array}$ & PA & Streak ovaries & $\begin{array}{l}\text { Alopecia, deafness, hypogonadism, diabetes, } \\
\text { intellectual disability }\end{array}$ & \#241080 & C2orf37 \\
\hline $\begin{array}{l}\text { Vanishing white matter } \\
\text { disease } \\
\text { Ovarioleukodystrophy }\end{array}$ & SA & $\begin{array}{l}\text { Ovarioleukodystrophy } \\
\text { streak ovaries }\end{array}$ & $\begin{array}{l}\text { Progressive cerebellar ataxia, spasticity, } \\
\text { cognitive impairment with white matter } \\
\text { lesions on brain imaging. Onset from early } \\
\text { infancy to adulthood }\end{array}$ & $\begin{array}{l}\# 603896 \\
\# 615889\end{array}$ & $\begin{array}{l}\text { EIF2B } \\
\text { AARS2 }\end{array}$ \\
\hline $\begin{array}{l}\text { Retinal dystrophy with } \\
\text { or without extraocular } \\
\text { anomalies }\end{array}$ & SA & & $\begin{array}{l}\text { Retinal dystrophy, goiter, intellectual } \\
\text { disability, hypogonadism }\end{array}$ & \#617175 & RCBTB1 \\
\hline $\begin{array}{l}\text { Progressive external } \\
\text { ophthalmoplegia }\end{array}$ & SA & Diminished follicle reserve & $\begin{array}{l}\text { Ptosis, progressive external ophthalmoplegia, } \\
\text { sensorineural hearing loss, axonal } \\
\text { neuropathy, muscle weakness, ataxia, } \\
\text { dysarthria, dysphagia and late onset } \\
\text { Parkinsonism }\end{array}$ & \#157640 & POLG \\
\hline $\begin{array}{l}\text { Acromesomelic } \\
\text { chondrodysplasia with } \\
\text { genital anomalies }\end{array}$ & PA & & $\begin{array}{l}\text { Severe brachydactyly with radial deviation of } \\
\text { the fingers, ulnar deviation of the hands, } \\
\text { fusion of the carpal/tarsal bones, aplasia of } \\
\text { the fibula, bilateral clubfeet with small broad } \\
\text { feet and short toes }\end{array}$ & \#609441 & $B M P R 1 B$ \\
\hline $\begin{array}{l}\text { Interphalangeal joint } \\
\text { synostosis }\end{array}$ & SA & & Symphalangism, hearing loss & \#185800 & NOG \\
\hline
\end{tabular}

${ }^{a} D S D$, Disorder of sexual differentiation; PA, primary amenorrhea; SA, secondary amenorrhea; US, ultrasound. See text for references and [13].

homozygous single nucleotide variant in the XRCC4 gene [47]. POI was reported in two patients with biallelic truncating mutations in the LIG4 gene [48]. These patients display short stature, microcephaly, and genomic instability or hypersensitivity to radiation. Similarly, another important DNA repair pathway, the Fanconi anemia (FANC) pathway, exists in numerous progenitor cells, including the germline. This pathway employs at least 20 proteins, including those encoded by the FANCA, FANC, and FANCG genes, and has been associated with POI [49]. Mouse models for several Fanc genes (a, c, d, e, f, g, i, m, n, o, p) evidenced gonadal hypoplasia with ovaries showing follicle depletion [50]. This appears to be due to reduced PGC numbers, though meiotic roles are also possible. Very recently a homozygous FANCM mutation was shown to underlie a familial case of nonsyndromic POI [51]. FANCM biallelic mutations predispose to cancer, in particular early-onset breast cancer in females and chemosensitivity 

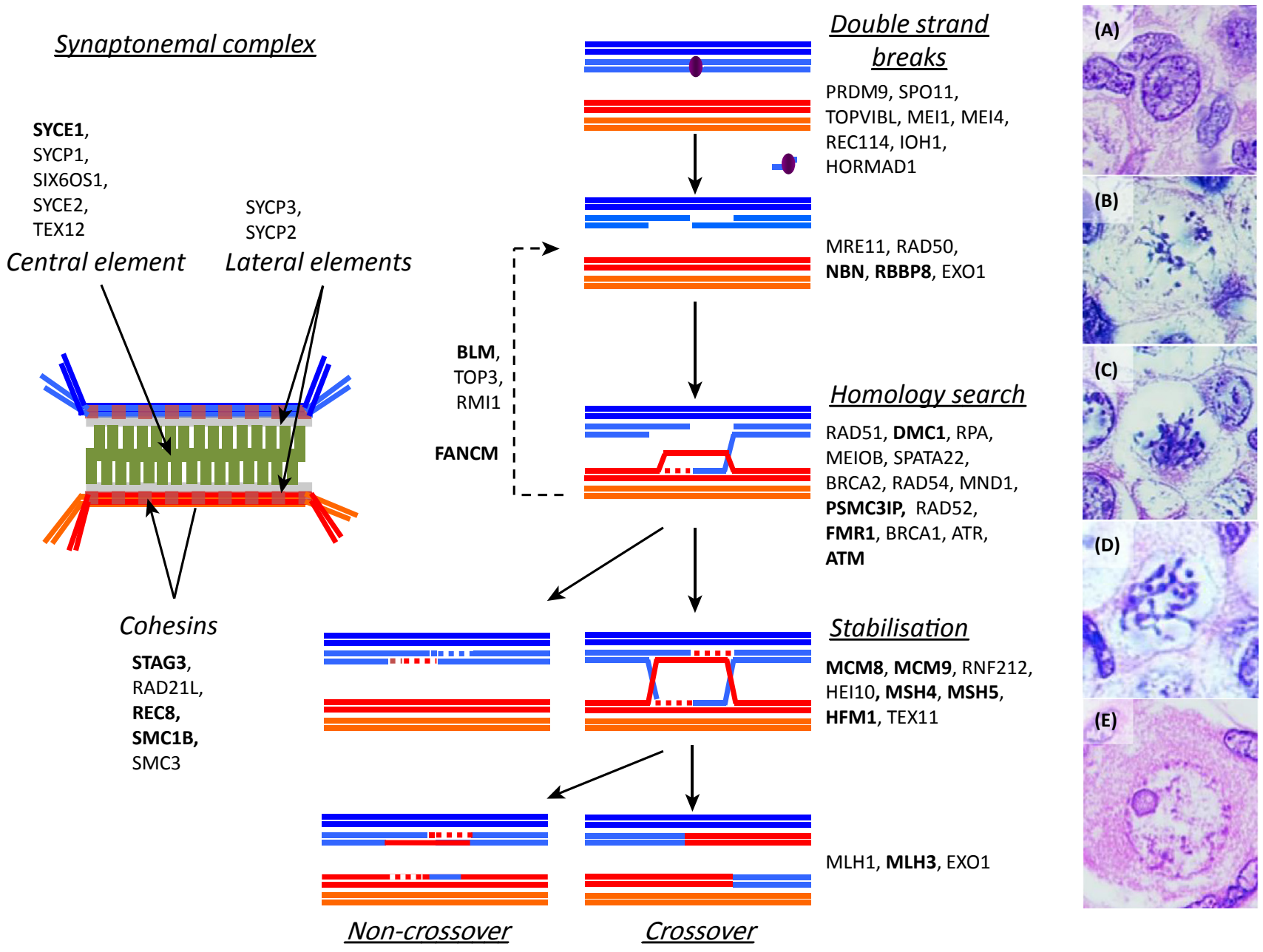

Trends in Endocrinology \& Metabolism

Figure 3. Female Infertility, Meiotic Recombination, and DNA Repair. The various steps of meiotic recombination and the specific genes involved (nonexhaustive, middle panel) are presented in the middle panel. Genes suspected in primary ovarian insufficiency cases are in bold. Left panel shows the structure of the synaptonemal complex required for completing recombination. Right panel presents representative germ cells at oogonial (A), leptotene (B), zygotene (C), pachytene (D), and diplotene (primordial follicle) (E) stages, from human ovaries at 8, 12, 15, 21, and 27 weeks postfertilization, respectively.

[52-54]. These findings clearly support a genetic link between infertility and DNA repair/cancer genes.

The recent identification of a genetic link between $\mathrm{POI}$ and tumor/cancer susceptibility genes (STAG3, MCM9, FANCM) makes the genetic diagnosis of all isolated cases of unexplained POI necessary, to perform enhanced genetic counseling and long-term follow-up. Indeed, POI patients can harbor mutations in such 'cancer susceptibility' genes. The large number of genes potentially involved will make these families among the most important involved in POI. 
Genes Involved in Syndromic POI (Figures 2 and 3 and Table 1)

The clinical presentations of syndromic POI are highly variable and are presented in Table 1.

\section{Perrault Syndrome (PS)}

Perrault syndrome (PS) is a genetically heterogeneous autosomal recessive syndrome, mainly characterized by ovarian dysfunction and sensorineural deafness (Table 1). Recently, a growing number of genes involved in PS were identified by NGS. These genes are implicated in mitochondrial functions or metabolism. In mouse models, genetic changes that cause perturbation in mitochondrial protein translation lead to hearing loss as a result of tissuespecific apoptosis [55]. Given the role of apoptosis in ovarian development, inappropriately timed apoptosis may also lead to POI. HARS2 [56] and LARS2 $[57,58]$ encode mitochondrial histidyl or leucyl-tRNA synthetases involved in translation of mitochondrially encoded genes. CLPP encodes a highly conserved endopeptidase component of a mitochondrial ATPdependent proteolytic complex, involved in degradation of unfolded or misfolded polypeptides [59-61]. C10orf2 encodes Twinkle, a mitochondrial primase-helicase essential for mitochondrial DNA replication $[62,63]$, yielding a mitochondrial DNA depletion syndrome and progressive external ophthalmoplegia. Very recently, mutations of ERAL1 and KIAA0391 were involved in PS. ERAL1 protein binds to the mitochondrial 12S rRNA and is involved in assembly of the small mitochondrial ribosomal subunit affecting mitochondrial respiration and function [64]. KIAA0391 encodes RNase P (PRORP) the metallonuclease subunit of the mitochondrial RNase $\mathrm{P}$ complex responsible for the $5^{\prime}$-end processing of mitochondrial precursor tRNAs [65].

Apart from mitochondrial functions, mutations in a multifunctional peroxisomal enzyme involved in fatty acid $ß$-oxidation and steroid metabolism, 17 $\beta$-hydroxysteroid dehydrogenase type 4 [HSD17B4, also known as D-bifunctional protein (DBP)] also cause PS [66-68]. Mutations of this gene were already identified in autosomal recessive mode in a severe disorder of peroxisomal fatty acid $\beta$-oxidation.

A combination of two homozygous mutations leading to a coincidental PS, one in CLDN14 involved in deafness and the other in shugoshin-like 2a (SGO2) encoding shugoshin2, likely involved in POI, have been described [69]. During meiosis in the mouse, SGO2 maintains the integrity of the cohesion complex that tethers sister chromatids. Unsolved cases of PS persist, indicating that novel genes will still be discovered $[70,71]$.

\section{Premature Aging Syndromes}

Laminopathy due to mutations in $L M N A$ encoding a nuclear envelope protein includes ovarian failure and premature aging. Malouf syndrome belongs to this condition [72]. HutchinsonGilford progeria Syndrome (HGPS) [73], caused by aberrant splicing of the LMNA gene and expression of a mutant product called progerin, comprises premature aging and lipodystrophies. Sometimes both syndromes occur together [73].

GAPO syndrome, another form of premature aging and premature follicle depletion, is caused by mutations of the anthrax toxin receptor 1 gene ANTXR1 [74]. The protein has been involved in cell attachment and migration. Additionally, it allows the interaction of cells and several components of the extracellular matrix by binding extracellular ligands with the actin of the cytoskeleton. 
Neurosensory Syndromes

Leukoencephalopathies are also a heterogeneous group of disorders associated with vanishing white matter and are seen in a subset of POI, yielding ovarioleukodystrophy. Mutations of a specific mitochondrial alanine aminoacyl-tRNA synthetase, AARS2, have been involved $[75,76]$. Another group of genes involved is EIF2B1 to EIF2B5 which encode the five subunits of the eukaryotic initiation factor 2B [77].

Mutations in RCBTB1 [78] are present in syndromes including inherited retinal dystrophy and POI. RCBTB1 is involved in ubiquitination, more specifically as a CUL3 substrate adaptor involved in stress-response to combat oxidative or electrophilic insults.

Mutations of the nuclear gene POLG encoding a mitochondrial DNA polymerase gamma can lead to POI with autosomal dominant progressive external ophthalmoplegia [79].

Defects in the respiratory chain or mitochondrial ATP synthase (complex V) result in mitochondrial dysfunction and defective energy production. Mutations of MT-ATP6/8 encoding two of the subunits of complex $V$ are associated with syndromes including cerebellar ataxia, peripheral neuropathy, diabetes mellitus, and POI [80].

\section{Skeletal Syndromes}

$\mathrm{POI}$ can occur in some skeletal syndromes, such as Demirhan syndrome, which is caused by mutations in BMPR1B [81].

Another condition including proximal symphalangism and $\mathrm{POI}$ is caused by mutations in NOG [82]. NOG protein is expressed in the ovaries and interacts with BMP, which plays an important role in ovarian function.

Genes Associated With Nonsyndromic POI

See Figures 2 and 3.

\section{Regulation of PF Recruitment}

The majority of PF will remain dormant until stimulatory signals or a break from inhibitory signals induces activation. PF recruitment is initiated in mice after birth at postnatal day 4-5, and in humans at 17 weeks of gestation (Figure 1).

Various oocyte-expressed signaling and/or transcription factors have been identified to maintain the quiescent state (Foxo3, Lhx8) or, in contrast, to activate PF growth (Sohlh1, Sohlh2, Nobox) [83] (Figure 2). Interestingly, Foxo3 and Lhx8 are the effectors of the PI3K/Akt signaling pathway [84]. Targeted (oocyte-specific) deletion of stimulating factors (Kit, Pdpk1, Rptor, Rps6) of this pathway blocks follicular activation and induces PF apoptosis, whereas loss of the inhibiting factors (Pten, Cdkn1b, Tsc1, Tsc2, Stk11) results in premature and global activation of PF [85] (Figure 2).

A characteristic of PF activation is the transition of squamous pregranulosa cells to cuboidal granulosa cells. Failure thereof results in an arrest at the primordial stage, followed by oocyte death and follicular depletion, as shown in FoxL2 knockout mice [86]. AMH, expressed during this transition, inhibits PF activation since Amh knockout mice display an accelerated exhaustion of the pool [87]. Several additional growth factors have been shown to activate PF recruitment (Figure 2). 


\section{Regulation of Follicle Growth}

Gonadotropin-Independent Phase: Role of Ovarian Growth Factors; Early follicle growth up to the large preantral stage is independent of gonadotropins in rodents and relies on intraovarian factors (Figure 2). It requires a coordinated dialog between the oocyte and granulosa cells, in which gap junctions and SMAD and PI3K/Akt pathways are important. The discovery that follicles in ovaries of Gdf9 knockout mice fail to develop beyond the primary stage was the first of a series showing the importance of factors involving SMAD signaling pathway in follicle development [88]. Furthermore, in the oocyte-knockout of Furin, a prohormone convertase responsible for proteolytic cleavage of TGF $\beta$ family members, follicle growth is arrested at the secondary stage [89]. Likewise, inhibition of the PI3K/Akt pathway by Kit or Kitlg deletions leads to the blockage of follicular growth at the primary follicle stage. Using targeted deletion or activation of Igf1, Igf1r, Irs2, Rictor, or Foxo3, it was shown that the PI3K/Akt signaling pathway not only plays a role in PF activation, but also in follicle survival and development beyond the primary stage $[90,91]$ (Figure 2).

Gonadotropin-Dependent Phase: Role of Gonadotropins; The progression through final stages of follicle development depends on the gonadotropins FSH and luteinizing hormone (LH) (Figure 2). The threshold for FSH sensitivity is determined by interplay between various stimulatory and inhibitory growth factors, such as IGF1 and various TGF $\beta$ family members tipping the balance to either follicle survival or atresia. Deletion of the Fshr yields an enhanced rate of atresia and follicles fail to progress to the antral stage [92]. Targeted deletion of the noncanonical progesterone receptor Pgrmc1 in granulosa cells suppressed antral follicle development and increased atresia [93]. Finally, LH action is indispensable for ovulation, meiotic resumption of the oocytes, and cumulus expansion. Loss of LH action therefore also results in infertility as follicle development is blocked at the antral stage [94]. In the absence of sex steroid action, the final stages of follicle development show abnormalities leading to follicular arrest, as illustrated in mouse models lacking (cell-specific) androgen or estrogen function $[95,96]$.

Defects in Human Genes in Nonsyndromic POI

Interestingly, there is an overlap between genes involved in the onset of puberty, normal reproductive aging, and $\mathrm{POI}$ [97]. We will present only recent data or selected examples of genes that illustrate the precaution that must be taken in the interpretation of genetic data and comparison with animal models.

\section{Genes Involved in Establishment of the PF Pool and Maturation to Primary Follicles;}

Heterozygous variants of SOHLH1 and SOHLH2 have been found in POI [98]. Interestingly, two families harboring a homozygous single-base deletion in the coding region or a premature stop codon of SOHLH1 [99] had PA, lack of secondary sex characteristics, and nonvisualized ovaries.

A recessive missense mutation in Nucleoporin-107 was identified in a consanguineous family of Palestinian origin [100]. NUP107 is a component of the nuclear pore complex, and the NUP107-associated protein SEH1 is required for oogenesis in Drosophila. In Drosophila, Nup107 knockdown in somatic gonadal cells resulted in female sterility, whereas males were fully fertile. Nup107 mutations may compromise the meiotic DNA damage response, leading to oocyte death.

A heterozygous stop codon was identified in the eukaryotic translation initiation factor $4 \mathrm{E}$ nuclear import factor 1 gene elF4ENIF1 in familial POI with dominant inheritance in three 
generations [101]. The gene plays an important role in oocyte development in organisms from Drosophila to mice.

Heterozygous mutations of the Newborn ovary homeobox (NOBOX) transcription factor have been reported in women with sporadic POI [28,102,103]. Contrasting with the knockout mouse model, which displays accelerated postnatal oocyte loss due to a defect in germ cell cyst breakdown [104], patients with NOBOX mutations may have PA or SA with follicles detected by histology in the ovaries in adulthood [102]. This may be due to the fact that the human mutations caused only partial loss of function in vitro. Functional studies are thus critical before any comparison with animal models and before any conclusion on the human physiological role of a gene can be established. Interestingly, a prevalence of $5.6 \%$ and $6.2 \%$ of heterozygous mutations has been detected in different cohorts, making this gene potentially one of the most frequent causes of $\mathrm{POI}$ in humans, provided that causality of the heterozygous variants is proven. Recently, a homozygous truncated variant of NOBOX has been described [105], with complete loss of function in vitro in patients with PA, but with no ovarian phenotype. Fertility of the heterozygous mother excludes a mechanism of haploinsufficiency, as previously proposed.

\section{Genes Involved in the Maturation and Growth from Primary to Ovulatory Follicles;}

The two steroid hormone receptors, for estrogens (ESR1) and androgens (AR), are positive regulators of follicular maturation. Two families with homozygous mutations of ESR1 have been described. The probands had PA without breast development, very high estrogen plasma concentrations, and multicystic ovaries [106,107]. Functional studies reveal altered estrogen signaling.

Interestingly, a continuum of phenotypes is associated with FSHR mutations, varying from absence of pubertal maturation to normal breast development with SA, according to severity of the receptor inactivation [108-111]. The first mutation described in the Finnish population was associated with the existence of preantral or rare antral follicles in the ovaries [108]. However, functional studies have shown that it was a partial loss of function mutation [112]. A complete loss of function mutation of the FSHR has also been described, causing PA and complete block of follicular maturation after the primary stage [113]. Remarkably, there was an increased density of small follicles when compared with an age-matched woman. Thus, the gonadotropin-dependent growth phase in humans starts at the primary follicle stage, contrary to rodents, in which preantral follicles are observed in ovaries of mice deficient in Fshb or Fshr (see above). Thus caution must be taken before extrapolating data from mouse models to humans. Partial mutations of the FSHR are associated with SA and the presence of different sized antral follicles, depending on severity of the mutation [114]. Of note, there is a correlation between the phenotype of the patients and the molecular studies. Because of the existence of follicles in the ovaries, in vitro maturation may be obtained and fertility restored ([115] and see below).

Mutations in the other gonadotropin receptor gene, LHCGR, cause POI with SA, anovulation, and recurrent cyst formation. In the affected families, disorders of sex differentiation are found in male relatives with hypogonadism due to Leydig cell hypoplasia $[116,117]$.

The first involvement of BMP15 in POI was reported in an Italian family with 46,XX ovarian dysgenesis [118]. Since then, several heterozygous and one homozygous BMP15 variant have been associated with PA or SA, but streak ovaries without follicles have been found using US, which was interpreted as premature depletion of the OR [118]. Functional studies suggest impaired production of the mature protein or, in some cases, a dominant negative effect [118]. 
However, most of the variants detected occur in the heterozygous state, and BMP15 haploinsufficiency was proposed to have a predisposing impact for POI. It was also proposed that reduced BMP15 dosage would contribute to the ovarian phenotype of Turner syndrome patients [119]. These conclusions were challenged by a very recent work on a family with a BMP15 knockout-like effect [120], with both parents bearing deletions in the proregion of the BMP15 precursor. The heterozygous mother conceived normally and had three children. Thus, it seems that haploinsufficiency is not involved in humans. Most of the mutations of BMP15 described were heterozygous and a mechanism of haploinsufficiency or a dominant negative effect was suspected but most often not demonstrated, making it impossible to implicate the corresponding gene as the unique cause of $\mathrm{POI}$. Additional genetic mutations in an oligogenic mode of inheritance and/or environmental factors must be involved. Despite streak ovaries, $\mathrm{AMH}$ was initially detectable in the two POI sisters bearing both deletions of BMP15, supporting the presence of an OR [120]. Five years later, however, AMH was not detected in both sisters, probably because of exhaustion of the PF pool, and one sister had received an egg donation.

In case POI is due to a block in follicular maturation, urgent fertility preservation is needed to avoid follicular atresia.

A recent study showed a homozygous single-base deletion in the coding region of GDF9 in POI with PA [121], confirming the causative role of this gene.

\section{Innovative Treatments for POI}

The most frequent therapeutic approach of infertility of $\mathrm{POI}$ patients is embryo transfer from donated oocytes. Given the complexity of this therapeutic approach, couples requiring oocyte donation should discuss its medical, ethical, legal, and psychological aspects with medical experts. Recently, a new innovative fertility treatment has been developed for POI (Figure 4).

Premature activation of PFs caused by chemotherapy, particularly cyclophosphamide, is a significant cause of the disappearance of follicles from the ovaries. Fertility preservation through tissue cryopreservation before chemotherapy is therefore an important method for preventing POI [122]. Post-treatment, the tissue can be autotransplanted. Infants have been born as a result of the technique.

For cancer patients at high risk of reintroduction of the malignancy, such as leukemia, in vitro maturation of follicles all the way to metaphase II oocytes is a much needed therapy that still remains to be developed.

In early stages of ovarian insufficiency there are PFs left in the ovaries. Hence, cryopreservation of ovarian tissue as fertility preservation should be carried out as soon as the risk of follicular decrease has been identified. Although these PFs are inactive, Hovatta et al. [123] showed that human ovarian follicles can be activated when ovarian tissue is cut into small pieces and placed in organ culture. Recently, Hippo signaling was identified as the regulatory factor in this activation $[5,124]$. When residual follicles in ovarian tissue from POI patients were stimulated by cutting the tissue into small pieces, and subsequently exposed to phosphatase and tensin homolog (PTEN) inhibitors and protein kinase B (Akt) activators prior to transplantation, full oocyte maturation can be achieved [125] (Figure 4). Of note, PTEN is also an important tumor suppressor, and therefore its inactivation in vivo might be risky. After IVA, the follicles have to be stimulated to grow, and FSH stimulation is used in a similar manner as in ovulation induction or before in vitro fertilization treatments. The ovarian tissue has been transplanted back to patients after IVA and healthy infants have been born (Figure 4). This IVA method is useful for those 


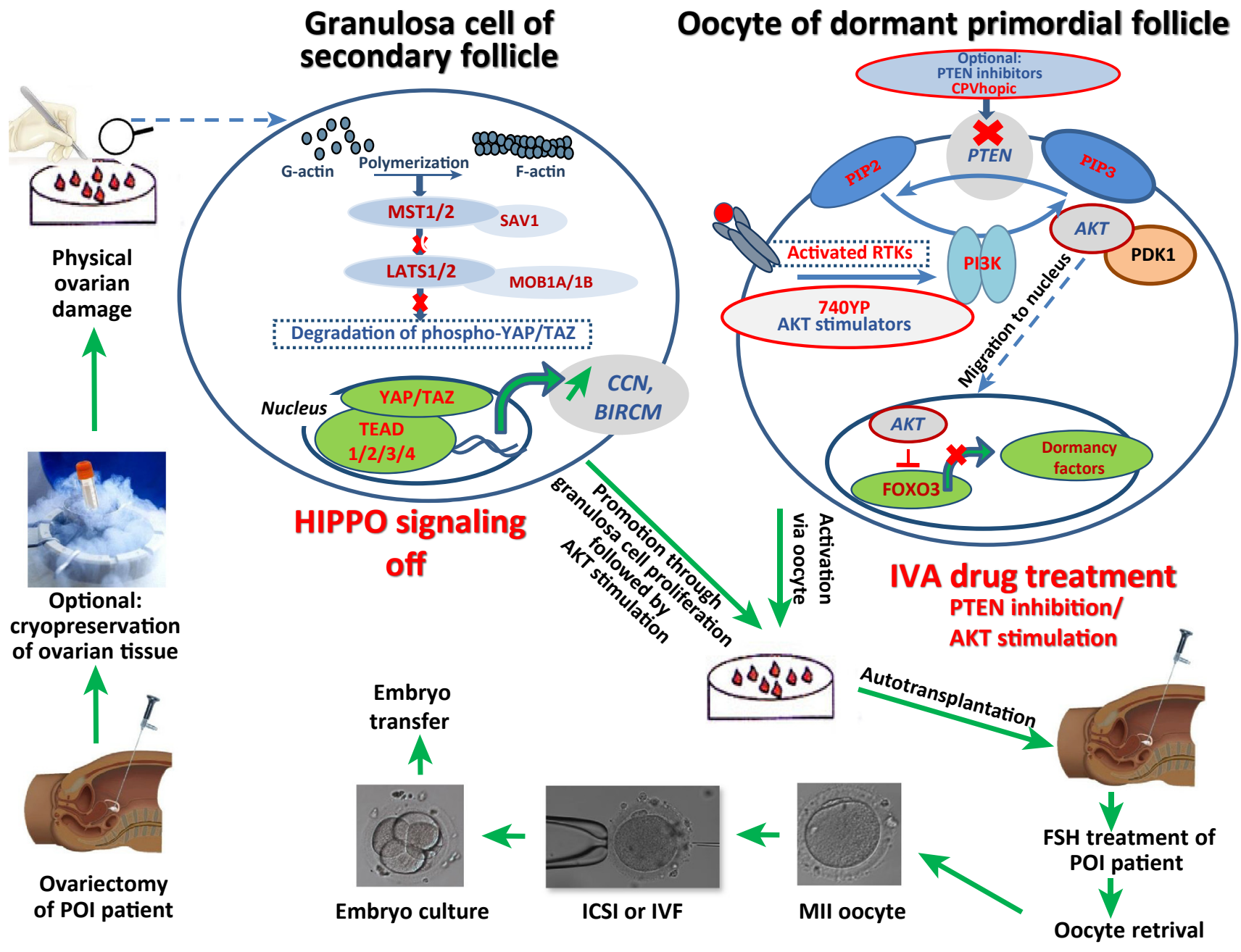

Trends in Endocrinology \& Metabolism

Figure 4. In Vitro Activation of Dormant Follicles. Ovarian cortical tissue is laparoscopically biopsied from the woman undergoing primary ovarian insufficiency (POI). The tissue is cut into slices for activation of Hippo signaling and initiation of follicular growth. Sliced tissue is then activated using a PTEN inhibitor or AKT stimulator in vitro for 24 hours. Thereafter, the tissue pieces can be transplanted back to the ovary of the donor woman. The activated follicles are stimulated using human recombinant follicle-stimulating hormone (FSH) for 6-10 days, until 15-17-mm sized antral follicles are seen by ultrasonography. The woman will be given human recombinant luteinizing hormone to induce the final maturation of the oocytes. The oocytes are collected 36 hours later using transvaginal ultrasound-guided needle aspiration. They are injected by intracytoplasmic sperm injection (ICSI) with sperm from the partner. The embryos are cultured for 3-5 days and the morphologically best embryo will be transferred to the intravaginal progesterone-treated female partner's womb. The rest of the embryos are cryo-stored for future transfers. IVA, In vitro activation; IVF, in vitro fertilization.

patients who may have residual follicles left in their ovaries (see flow chart in Figure 5 for POI diagnosis and treatment).

Ultimately, recent technological developments with induced pluripotent stem cells allow the reconstitution of complete oogenesis [126]. Currently this has only been achieved in the mouse, but advances with human cells now make it conceivable for modeling POI and would prove invaluable for supporting genetic diagnosis. In specific cases (e.g., altered follicle recruitment or growth), such models may prove useful for drug screening and selecting the most appropriate treatment. 


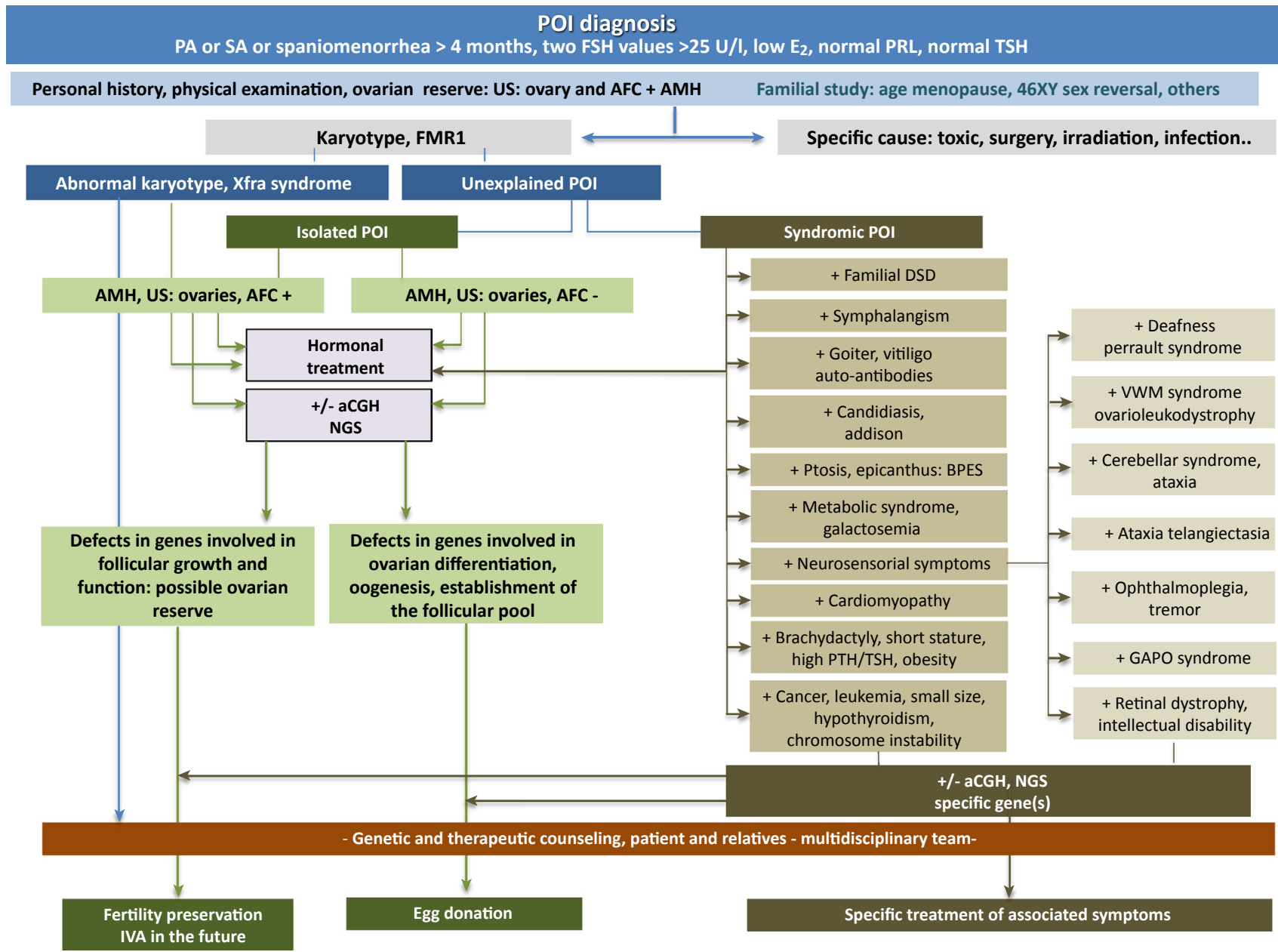

Trends in Endocrinology \& Metabolism

Figure 5. Flow Chart for Primary Ovarian Insufficiency Diagnosis and Treatment. After the initial diagnosis of primary ovarian insufficiency (POI), family investigation and evaluation of the follicular reserve by anti-Müllerian hormone (AMH) assay and antral follicular count (AFC) are performed. Specific causes are eliminated. In the case of unexplained POI, karyotype and FMR1 study are performed. In all cases hormonal treatment has to be started. In isolated POI, array comparative genomic hybridization (aCGH) or next generation sequencing (NGS) can highlight defects in genes involved in ovarian differentiation or in the establishment of the follicular pool. This, together with the undetectable ovarian reserve, will lead to genetic counseling in the patient and relatives and therapeutic counseling for the patient's infertility by a multidisciplinary team. If there is a wish to conceive, egg donation will be performed. In the case of a detectable ovarian reserve and/or a defect in genes involved in follicular maturation, genetic counselling will be performed in the patient and relatives and therapeutic counseling will lead to fertility preservation. In the future, in vitro activation (IVA) of small follicles might be performed. In syndromic POI, NGS of specific genes will be performed according to the clinical phenotype of the patient. Specific treatment of associated symptoms is needed. AFC antral follicle count; DSD, disorder of sexual differentiation; FSH, follicle-stimulating hormone; PA, primary amenorrhea; PRL, prolactin; PTH, parathyroid hormone; SA, secondary amenorrhea; TSH, thyroid-stimulating hormone; US, ultrasonography; VWM, vanishing white matter.

Other technological developments, such as tissue engineering to generate ovarian implants, are promising leads that may help restore fertility [127].

\section{Concluding Remarks and Future Perspectives}

Taken together, the vast technological advancements have provided valuable new information on the molecular pathophysiology of $\mathrm{POI}$ and its new diagnosis and treatment opportunities. Information derived from recent genetic studies has improved the accuracy of POI diagnosis and may reveal new targets for the treatment of infertility or for contraception in the future. 
Because of its increased nonreproductive morbidity and mortality (e.g., autoimmunity and tumors) POI should be followed by a multidisciplinary team. The very recent identification of a link between POI and tumor susceptibility makes the genetic diagnosis of all isolated cases of unexplained POI necessary. Also, POI as a genetic disorder becomes amenable to innovative therapies, unlike most other genetic diseases. This obviously necessitates the presence of remnant OR that has to be evaluated besides conventional methods by genetic studies (Figure 5). Indeed, the key question is: what is the state of the follicular pool in the POI patient? The mutated gene may provide important information on the OR, depending on its level of action during either establishment and/or maintenance of the follicular pool, or follicular growth. This belongs to the questions that will need to be answered in the future (see Outstanding Questions).

\section{Acknowledgements}

Apologies to those whose related publications were not cited due to space limitations. We thank Alain Gougeon for providing photographs of the different steps of follicular maturation.

\section{References}

1. European Society for Human Reproduction and Embryology (ESHRE) Guideline Group on POI et al. (2016) ESHRE Guideline: management of women with premature ovarian insufficiency. Hum. Reprod. 31, 926-937

2. Rossetti, R. et al. (2017) Genetics of primary ovarian insufficiency. Clin. Genet. 91, 183-198

3. Nelson, L.M. (2009) Clinical practice. Primary ovarian insufficiency. N. Engl. J. Med. 360, 606-614

4. La Marca, A. et al. (2013) Prediction of age at menopause from assessment of ovarian reserve may be improved by using body mass index and smoking status. PLoS One 8, e57005

5. Zhai, J. et al. (2016) In vitro activation of follicles and fresh tissue auto-transplantation in primary ovarian insufficiency patients. $\mathrm{J}$. Clin. Endocrinol. Metab. 101, 4405-4412

6. Vabre, P. et al. (2017) Environmental pollutants, a possible etiology for premature ovarian insufficiency: a narrative review of animal and human data. Environ. Health 16, 37

7. Craig, Z.R. et al. (2011) Endocrine-disrupting chemicals in ovarian function: effects on steroidogenesis, metabolism and nuclear receptor signaling. Reproduction 142, 633-646

8. Nilsson, E. et al. (2012) Environmentally induced epigenetic transgenerational inheritance of ovarian disease. PLOS One 7 , e36129

9. Silva, C.A. et al. (2014) Autoimmune primary ovarian insufficiency. Autoimmun. Rev. 13, 427-430

10. Tibiletti, M.G. et al. (1999) The idiopathic forms of premature menopause and early menopause show the same genetic pattern. Hum. Reprod. 14, 2731-2734

11. Vegetti, W. et al. (1998) Inheritance in idiopathic premature ovarian failure: analysis of 71 cases. Hum. Reprod. 13, 17961800

12. van Kasteren, Y.M. et al. (1999) Familial idiopathic premature ovarian failure: an overrated and underestimated genetic disease? Hum. Reprod. 14, 2455-2459

13. Qin, $Y$. et al. (2015) Genetics of primary ovarian insufficiency: new developments and opportunities. Hum. Reprod. Update $21,787-808$

14. Man, L. et al. (2017) Fragile X-associated diminished ovarian reserve and primary ovarian insufficiency from molecular mechanisms to clinical manifestations. Front. Mol. Neurosci. 10, 290

15. Baker, T.G. (1963) A quantitative and cytological study of germ cells in human ovaries. Proc. R. Soc. Lond. B Biol. Sci. 158, $417-433$

16. Guo, F. et al. (2015) The transcriptome and DNA methylome landscapes of human primordial germ cells. Cell 161, 14371452
17. Grive, K.J. et al. (2016) TAF4b regulates oocyte-specific genes essential for meiosis. PLoS Genet. 12, e1006128

18. Abby, E. et al. (2016) Implementation of meiosis prophase programme requires a conserved retinoid-independent stabilizer of meiotic transcripts. Nat. Commun. 7, 10324

19. Bailey, A.S. et al. (2017) The conserved RNA helicase YTHDC2 regulates the transition from proliferation to differentiation in the germline. eLife 6, e26116

20. Pepling, M.E. (2006) From primordial germ cell to primordia follicle: mammalian female germ cell development. Genesis 44 622-632

21. Grive, K.J. and Freiman, R.N. (2015) The developmental origins of the mammalian ovarian reserve. Development 142, 25542563

22. Chen, Y. et al. (2007) Estradiol, progesterone, and genistein inhibit oocyte nest breakdown and primordial follicle assembly in the neonatal mouse ovary in vitro and in vivo. Endocrinology 148, 3580-3590

23. Pepling, M.E. and Spradling, A.C. (2001) Mouse ovarian germ cell cysts undergo programmed breakdown to form primordial follicles. Dev. Biol. 234, 339-351

24. Matzuk, M.M. and Lamb, D.J. (2002) Genetic dissection of mammalian fertility pathways. Nat. Cell Biol. 4, s41-s49

25. Baudat, F. et al. (2013) Meiotic recombination in mammals localization and regulation. Nat. Rev. Genet. 14, 794-806

26. Caburet, S. et al. (2014) Mutant cohesin in premature ovarian

27. Winters, $T$. et al. (2014) Meiotic cohesin STAG3 is required fo chromosome axis formation and sister chromatid cohesion. EMBO J. 33, 1256-1270

28. Bouilly, J. et al. (2016) Identification of multiple gene mutations accounts for a new genetic architecture of primary ovarian insufficiency. J. Clin. Endocrinol. Metab. 101, 4541-4550

29. de Vries, L. et al. (2014) Exome sequencing reveals SYCE1 mutation associated with autosomal recessive primary ovarian insufficiency. J. Clin. Endocrinol. Metab. 99, E2129-E2132

30. Bolcun-Filas, E. et al. (2009) Mutation of the mouse Syce1 gene disrupts synapsis and suggests a link between synaptonema complex structural components and DNA repair. PLOS Genet. 5, e1000393

31. Lee, K.Y. et al. (2015) MCM8-9 complex promotes resection of double-strand break ends by MRE11-RAD50-NBS1 complex. Nat. Commun. 6, 7744

32. AlAsiri, S. et al. (2015) Exome sequencing reveals MCM8 mutation underlies ovarian failure and chromosomal instability. J. Clin. Invest. 125, 258-262 failure. N. Engl. J. Med. 370, 943-949

\section{Outstanding Questions}

Does investigation of the genetic causes of $\mathrm{POI}$ improve our understanding of the regulation of meiosis in mammals? The vast majority of meiotic genes are shared by rodents and primates.

What is the interplay between DNA repair in cancer and infertility? Several genes involved in genomic stability are also associated with infertility. Based on the massive generation of hundreds of DSBs that need repair in each meiotic cell, this might not appear as a surprise. We may even consider that this extraordinary requirement of DNA repair could explain why genetic variants that only mildly impact genetic stability in somatic cells are unraveled in the case of infertility. In this case, a broader consideration of cancer predisposition in families with cases of infertility is likely a wise option.

Can we demonstrate systematically the genetic etiology of $\mathrm{POI}$ ? It has been proposed that $\mathrm{POI}$ might frequently be a multigenic disease. Additionally, the functional demonstration of the pathogenicity of variants can be tedious and also depends on the genetic background. Therefore, induced pluripotent cells could offer a fantastic possibility to ascertain the genetic diagnosis.

Although mouse knockout studies in particular have identified several pathways that play a crucial role in PF recruitment, we still lack full understanding of the mechanisms that control gradual recruitment, as loss of function of the majority of these factors causes global activation of PFs.

How efficient is the in vitro activation of dormant follicles on a larger scale? We may reach the answer in the future, when more centers apply and test this. A question has been raised: how do we distinguish such pregnancies from the extremely rare, but not impossible, spontaneous pregnancies among the women with resumptive POI?

Can genetics provide information on the existence of a persistent follicular pool that is small, or comprises only PFs? Recent studies using near-infrared imaging of $\mathrm{FSH}$ receptors allowed the monitoring of undetectable 
33. Wood-Trageser, M.A. et al. (2014) MCM9 mutations are associated with ovarian failure, short stature, and chromosomal instability. Am. J. Hum. Genet. 95, 754-762

34. Tenenbaum-Rakover, Y. et al. (2015) Minichromosome maintenance complex component 8 (MCM8) gene mutations result in primary gonadal failure. J. Med. Genet. 52, 391-399

35. Fauchereau, F. etal. (2016) A non-sense MCM9 mutation in a familial case of primary ovarian insufficiency. Clin. Genet. 89, 603-607

36. Goldberg, Y. et al. (2015) Mutated MCM9 is associated with predisposition to hereditary mixed polyposis and colorectal cancer in addition to primary ovarian failure. Cancer Genet. 208, 621-624

37. Mandon-Pépin, B. et al. (2008) Genetic investigation of four meiotic genes in women with premature ovarian failure. Eur. J. Endocrinol. 158, 107-115

38. Zangen, D. et al. (2011) XX ovarian dysgenesis is caused by a PSMC3IP/HOP2 mutation that abolishes coactivation of estrogen-driven transcription. Am. J. Hum. Genet. 89, 572-579

39. Wang, J. et al. (2014) Mutations in HFM1 in recessive primary ovarian insufficiency. N. Engl. J. Med. 370, 972-974

40. Pu, D. et al. (2016) Association analysis between HFM1 variation and primary ovarian insufficiency in Chinese women. Clin. Genet. 89, 597-602

41. Carlosama, C. et al. (2017) A homozygous donor splice-site mutation in the meiotic gene MSH4 causes primary ovarian insufficiency. Hum. Mol. Genet. 26, 3161-3166

42. Guo, T. et al. (2017) Mutations in MSH5 in primary ovarian insufficiency. Hum. Mol. Genet. 26, 1452-1457

43. Fu, W. et al. (2017) Human RECQ helicase pathogenic variants, population variation and "missing" diseases. Hum. Mutat. 38, 193-203

44. Lu, L. et al. (2017) Aging in Rothmund-Thomson syndrome and related RECQL4 genetic disorders. Ageing Res. Rev. 33, 30-35

45. Wu, P.-F. et al. (2017) A novel splice-site mutation of WRN (c. IVS28+2T >C) identified in a consanguineous family with Werner Syndrome. Mol. Med. Rep. 15, 3735-3738

46. Qin, Y. et al. (2015) CSB-PGBD3 mutations cause premature ovarian failure. PLoS Genet. 11, e1005419

47. de Bruin, C. et al. (2015) An XRCC4 splice mutation associated with severe short stature, gonadal failure, and early-onset metabolic syndrome. J. Clin. Endocrinol. Metab. 100, E789-E798

48. Murray, J.E. et al. (2014) Extreme growth failure is a common presentation of ligase IV deficiency. Hum. Mutat. 35, 76-85

49. Giri, N. et al. (2007) Endocrine abnormalities in patients with Fanconi anemia. J. Clin. Endocrinol. Metab. 92, 2624-2631

50. Fu, C. et al. (2016) Primary ovarian insufficiency induced by Fanconi anemia E mutation in a mouse model. PLoS One 11, e0144285

51. Fouquet, B. et al. (2017) A homozygous FANCM mutation underlies a familial case of non-syndromic primary ovarian insufficiency. eLife 6, e30490

52. Michl, J. et al. (2016) Interplay between Fanconi anemia and homologous recombination pathways in genome integrity. EMBO J. 35, 909-923

53. Bogliolo, M. et al. (2017) Biallelic truncating FANCM mutations cause early-onset cancer but not Fanconi anemia. Genet. Med. Published online August 24, 2017. http://dx.doi.org/10.1038/ gim.2017.124

54. Catucci, l. et al. (2017) Individuals with FANCM biallelic mutations do not develop Fanconi anemia, but show risk for breast cancer, chemotherapy toxicity and may display chromosome fragility. Genet. Med. Published online August 24, 2017. http:// dx.doi.org/10.1038/gim.2017.123

55. Raimundo, N. et al. (2012) Mitochondrial stress engages E2F1 apoptotic signaling to cause deafness. Cell 148, 716-726

56. Pierce, S.B. et al. (2011) Mutations in mitochondrial histidyl tRNA synthetase HARS2 cause ovarian dysgenesis and sensorineural hearing loss of Perrault syndrome. Proc. Natl. Acad. Sci. U. S. A. $108,6543-6548$
57. Pierce, S.B. et al. (2013) Mutations in LARS2, encoding mitochondrial leucyl-tRNA synthetase, lead to premature ovarian failure and hearing loss in Perrault syndrome. Am. J. Hum. Genet. 92, 614-620

58. Soldà, G. et al. (2016) First independent replication of the involvement of LARS2 in Perrault syndrome by whole-exome sequencing of an Italian family. J. Hum. Genet. 61, 295-300

59. Jenkinson, E.M. et al. (2013) Perrault syndrome is caused by recessive mutations in CLPP, encoding a mitochondrial ATPdependent chambered protease. Am. J. Hum. Genet. 92, 605613

60. Ahmed, S. et al. (2015) Exome analysis identified a novel missense mutation in the CLPP gene in a consanguineous Saud family expanding the clinical spectrum of Perrault Syndrome type-3. J. Neurol. Sci. 353, 149-154

61. Dursun, F. et al. (2016) A novel missense mutation in the CLPP gene causing Perrault syndrome type 3 in a Turkish family. $J$. Clin. Res. Pediatr. Endocrinol. 8, 472-477

62. Morino, H. et al. (2014) Mutations in Twinkle primase-helicase cause Perrault syndrome with neurologic features. Neurology 83, 2054-2061

63. Ołdak, M. et al. (2017) Novel neuro-audiological findings and further evidence for TWNK involvement in Perrault syndrome. J. Transl. Med. 15, 25

64. Chatzispyrou, I.A. et al. (2017) A homozygous missense mutation in ERAL1, encoding a mitochondrial rRNA chaperone, causes Perrault syndrome. Hum. Mol. Genet. 26, 2541-2550

65. Hochberg, I. et al. (2017) A homozygous variant in mitochondria RNase $P$ subunit PRORP is associated with Perrault syndrome characterized by hearing loss and primary ovarian insufficiency. bioRxiv Published online July 27, 2017. http://dx.doi.org/ $10.1101 / 168252$

66. Pierce, S.B. et al. (2010) Mutations in the DBP-deficiency protein HSD17B4 cause ovarian dysgenesis, hearing loss, and ataxia of Perrault Syndrome. Am. J. Hum. Genet. 87, 282-288

67. Amor, D.J. et al. (2016) Heterozygous mutations in HSD17B cause juvenile peroxisomal D-bifunctional protein deficiency. Neurol. Genet. 2, e114

68. Chen, K. et al. (2017) A homozygous missense variant in HSD17B4 identified in a consanguineous Chinese Han family with type II Perrault syndrome. BMC Med. Genet. 18, 91

69. Faridi, R. et al. (2017) Mutations of SGO2 and CLDN14 collec tively cause coincidental Perrault syndrome. Clin. Genet. 91 328-332

70. Lerat, J. et al. (2016) An application of NGS for molecular investigations in Perrault syndrome: study of 14 families and review of the literature. Hum. Mutat. 37, 1354-1362

71. Demain, L.A. et al. (2017) Genetics of mitochondrial dysfunction and infertility. Clin. Genet. 91, 199-207

72. Silfeler, D.B. et al. (2014) Malouf syndrome with hypergonadotropic hypogonadism and cardiomyopathy: two-case report and literature review. Case Rep. Obstet. Gynecol. 2014, 275710

73. Gonzalo, S. et al. (2017) Hutchinson-Gilford progeria syndrome: a premature aging disease caused by LMNA gene mutations. Ageing Res. Rev. 33, 18-29

74. Benetti-Pinto, C.L. et al. (2016) GAPO syndrome: a new syndromic cause of premature ovarian insufficiency. Climacteric 19 $594-598$

75. Dallabona, C. et al. (2014) Novel (ovario) leukodystrophy related to AARS2 mutations. Neurology 82, 2063-207

76. Lakshmanan, R. et al. (2017) Redefining the phenotype of ALSP and AARS2 mutation-related leukodystrophy. Neurol. Genet. 3

77. Lynch, D.S. et al. (2017) Clinical and genetic characterization of leukoencephalopathies in adults. Brain J. Neurol. 140, $1204-$ 121

78. Coppieters, F. et al. (2016) Isolated and syndromic retinal dystrophy caused by biallelic mutations in RCBTB1, a gene implicated in ubiquitination. Am. J. Hum. Genet. 99, 470-480 secondary follicles using US [128]. Identification of the genetic cause could be a possible predictor of an OR if a gene involved in follicular growth is identified. On the contrary, mutations in meiosis or DNA repair genes will most often exclude such a possibility (see flow chart in Figure 5 for diagnosis and treatment of $\mathrm{POI}$ ). 
79. Luoma, P. et al. (2004) Parkinsonism, premature menopause, and mitochondrial DNA polymerase gamma mutations: clinical and molecular genetic study. Lancet 364, 875-882

80. Kytövuori, L. et al. (2016) A novel mutation m.8561C > G in MTATP6/8 causing a mitochondrial syndrome with ataxia, peripheral neuropathy, diabetes mellitus, and hypergonadotropic hypogonadism. J. Neurol. 263, 2188-2195

81. Demirhan, O. et al. (2005) A homozygous BMPR1B mutation causes a new subtype of acromesomelic chondrodysplasia with genital anomalies. J. Med. Genet. 42, 314-317

82. Kadi, N. et al. (2012) Proximal symphalangism and premature ovarian failure. Joint Bone Spine 79, 83-84

83. Jagarlamudi, K. and Rajkovic, A. (2012) Oogenesis: transcriptional regulators and mouse models. Mol. Cell. Endocrinol. 356, 31-39

84. Ren, Y. et al. (2015) Lhx8 regulates primordial follicle activation and postnatal folliculogenesis. BMC Biol. 13, 39

85. Reddy, P. et al. (2010) Mechanisms maintaining the dormancy and survival of mammalian primordial follicles. Trends Endocrinol. Metab. 21, 96-103

86. Schmidt, D. et al. (2004) The murine winged-helix transcription factor Foxl2 is required for granulosa cell differentiation and ovary maintenance. Development 131, 933-942

87. Visser, J.A. et al. (2006) Anti-Müllerian hormone: a new marker for ovarian function. Reproduction 131, 1-9

88. Otsuka, F. et al. (2011) Integral role of GDF-9 and BMP-15 in ovarian function. Mol. Reprod. Dev. 78, 9-21

89. Meng, T.-G. et al. (2017) Oocyte-specific deletion of furin leads to female infertility by causing early secondary follicle arrest in mice. Cell Death Dis. 8, e2846

90. Chen, Z. et al. (2015) Rictor/mTORC2 pathway in oocytes regulates folliculogenesis, and its inactivation causes premature ovarian failure. J. Biol. Chem. 290, 6387-6396

91. Liu, L. et al. (2007) Infertility caused by retardation of follicular development in mice with oocyte-specific expression of Foxo3a. Dev. Camb. Engl. 134, 199-209

92. Abel, M.H. et al. (2000) The effect of a null mutation in the folliclestimulating hormone receptor gene on mouse reproduction. Endocrinology 141, 1795-1803

93. Peluso, J.J. and Pru, J.K. (2014) Non-canonical progesterone signaling in granulosa cell function. Reproduction 147, R169R178

94. Pakarainen, T. et al. (2005) Knockout of luteinizing hormone receptor abolishes the effects of follicle-stimulating hormone on preovulatory maturation and ovulation of mouse graafian follicles. Mol. Endocrinol. 19, 2591-2602

95. Hamilton, K.J. et al. (2014) Estrogen hormone physiology: reproductive findings from estrogen receptor mutant mice. Reprod. Biol. 14, 3-8

96. Walters, K.A. (2015) Role of androgens in normal and pathological ovarian function. Reproduction 149, R193-R218

97. Perry, J.R.B. et al. (2015) Molecular insights into the aetiology of female reproductive ageing. Nat. Rev. Endocrinol. 11, 725-734

98. Qin, Y. et al. (2014) Novel variants in the SOHLH2 gene are implicated in human premature ovarian failure. Fertil. Steril. 101, 1104-1109

99. Bayram, Y. et al. (2015) Homozygous loss-of-function mutations in SOHLH1 in patients with nonsyndromic hypergonadotropic hypogonadism. J. Clin. Endocrinol. Metab. 100, E808-E814

100. Weinberg-Shukron, A. et al. (2015) A mutation in the nucleoporin-107 gene causes $X X$ gonadal dysgenesis. J. Clin. Invest. 125, 4295-4304

101. Kasippillai, T. et al. (2013) Mutations in elF4ENIF1 are associated with primary ovarian insufficiency. J. Clin. Endocrinol. Metab. 98, E1534-E1539

102. Bouilly, J. et al. (2011) Novel NOBOX loss-of-function mutations account for $6.2 \%$ of cases in a large primary ovarian insufficiency cohort. Hum. Mutat. 32, 1108-1113
103. Ferrari, I. et al. (2016) Impaired protein stability and nuclea localization of NOBOX variants associated with premature ovarian insufficiency. Hum. Mol. Genet. 25, 5223-5233

104. Rajkovic, A. et al. (2004) NOBOX deficiency disrupts early folliculogenesis and oocyte-specific gene expression. Science $305,1157-1159$

105. Li, L. et al. (2017) A homozygous NOBOX truncating variant causes defective transcriptional activation and leads to primary ovarian insufficiency. Hum. Reprod. 32, 248-255

106. Bernard, V. et al. (2017) Familial multiplicity of estrogen insensitivity associated with a loss-of-function ESR1 mutation. J. Clin. Endocrinol. Metab. 102, 93-99

107. Quaynor, S.D. et al. (2013) Delayed puberty and estrogen resis tance in a woman with estrogen receptor $\alpha$ variant. N. Engl. $J$. Med. 369, 164-171

108. Aittomäki, K. et al. (1995) Mutation in the follicle-stimulating hormone receptor gene causes hereditary hypergonadotropic ovarian failure. Cell 82, 959-968

109. Bramble, M.S. et al. (2016) A novel follicle-stimulating hormone receptor mutation causing primary ovarian failure: a fertility application of whole exome sequencing. Hum. Reprod. 31 905-914

110. Katari, S. et al. (2015) Novel inactivating mutation of the FSH receptor in two siblings of Indian origin with premature ovarian failure. J. Clin. Endocrinol. Metab. 100, 2154-2157

111. França, M.M. et al. (2017) A novel homozygous missense FSHR variant associated with hypergonadotropic hypogonadism in two siblings from a Brazilian family. Sex. Dev. 11, 137-142

112. Rannikko, A. et al. (2002) Functional characterization of the human FSH receptor with an inactivating Ala189Val mutation. Mol. Hum. Reprod. 8, 311-317

113. Meduri, G. et al. (2003) Delayed puberty and primary amenorrhea associated with a novel mutation of the human folliclestimulating hormone receptor: clinical, histological, and molecular studies. J. Clin. Endocrinol. Metab. 88, 3491-3498

114. Meduri, G. et al. (2008) Molecular pathology of the FSH receptor: new insights into FSH physiology. Mol. Cell. Endocrinol. 282 130-142

115. Grynberg, M. et al. (2013) First birth achieved after in vitro maturation of oocytes from a woman endowed with multiple antral follicles unresponsive to follicle-stimulating hormone. $J$. Clin. Endocrinol. Metab. 98, 4493-4498

116. Fonseca, D.J. et al. (2015) Next generation sequencing in women affected by nonsyndromic premature ovarian failure displays new potential causative genes and mutations. Ferti. Steril. 104, 154-162

117. Bentov, Y. et al. (2012) A novel luteinizing hormone/chorionic gonadotropin receptor mutation associated with amenorrhea, low oocyte yield, and recurrent pregnancy loss. Fertil. Steril. 97, $1165-1168$

118. Persani, L. et al. (2014) The fundamental role of bone morphogenetic protein 15 in ovarian function and its involvement in female fertility disorders. Hum. Reprod. Update 20, 869-883

119. Castronovo, C. et al. (2014) Gene dosage as a relevant mechanism contributing to the determination of ovarian function in Turner syndrome. Hum. Reprod. 29, 368-379

120. Mayer, A. et al. (2017) BMP15 "knockout-like" effect in familia premature ovarian insufficiency with persistent ovarian reserve. Clin. Genet. 92, 208-212

121. França, M.M. et al. (2017) Identification of the first homozygous 1-bp deletion in GDF9 gene leading to primary ovarian insufficiency by using targeted massively parallel sequencing. Clin Genet. 93, 408-411

122. Donnez, J. and Dolmans, M.-M. (2017) Fertility preservation in women. N. Engl. J. Med. 377, 1657-1665

123. Hovatta, O. et al. (1997) Extracellular matrix improves survival of both stored and fresh human primordial and primary ovarian ollicles in long-term culture. Hum. Reprod. 12, 1032-1036 
124. Kawamura, K. et al. (2013) Hippo signaling disruption and Akt stimulation of ovarian follicles for infertility treatment. Proc. Natl. Acad. Sci. U. S. A. 110, 17474-17479

125. Adhikari, D. et al. (2012) The safe use of a PTEN inhibitor for the activation of dormant mouse primordial follicles and generation of fertilizable eggs. PLoS One 7, e39034

126. Hikabe, O. et al. (2016) Reconstitution in vitro of the entire cycle of the mouse female germ line. Nature 539, 299-303
127. Laronda, M.M. et al. (2017) A bioprosthetic ovary created using 3D printed microporous scaffolds restores ovarian function in sterilized mice. Nat. Commun. 8, 15261

128. Feng, Y. et al. (2017) Live imaging of follicle stimulating hormone receptors in gonads and bones using near infrared II fluorophore. Chem. Sci. 8, 3703-3711 